\title{
Haşhaş Kapsülü Küspesinin Sabit Yataklı Reaktörde Katalitik Pirolizi
}

\author{
Derya Yeşim Hopa ${ }^{1}$, Nazan Y1lmaz ${ }^{2 *}$ \\ ${ }^{1}$ Afyon Kocatepe Üniversitesi, Mühendislik Fakültesi, Kimya Mühendisliği Bölümü, Afyon, Türkiye, (ORCID: 0000-0003-0161-1404) \\ ${ }^{2}$ Afyon Kocatepe Üniversitesi, Mühendislik Fakültesi, Kimya Mühendisliği Bölümü, Afyon, Türkiye, (ORCID: 0000-0002-2145-3098)
}

(İlk Geliş Tarihi 24 Eylül 2019 ve Kabul Tarihi 2 Kasım 2019)

(DOI: 10.31590/ejosat.624066)

ATIF/REFERENCE: Hopa, D. Y. \& Yılmaz, N. (2019). Haşhaş Kapsülü Küspesinin Sabit Yataklı Reaktörde Katalitik Pirolizi. Avrupa Bilim ve Teknoloji Dergisi, (17), 581-588.

$\ddot{O} \mathbf{z}$

İnsanlık tarihinde teknoloji, bilim ve sanayinin gelişmesi ile enerji türlerinin kullanımının arttığı görülmüştür. Biyokütle enerjisi yenilenebilir ve bol bulunan enerji kaynaklarından bir tanesidir. Biyokütleden piroliz işlemi ile gaz, sıvı (bioyağ) ve katı ürünler (char) elde edilemektedir. Piroliz ürünü olan biyoyağ yakıt olarak değerlendirilebilmektedir. Bu doğtultu da yapılan bu çalışmada, biyokütle olarak seçilen haşhaş küspesinden piroliz yöntemi ile biyoyağ eldesinde katalizörün biyoyağ ürün verimine etkisi araştırılmıştır. Piroliz işlemleri sabit yataklı piroliz reaktöründe $500^{\circ} \mathrm{C}$ sıcaklıkta, $10^{\circ} \mathrm{C} / \mathrm{dk} 1$ sıtma hızında, $1 \mathrm{~L} / \mathrm{dk}$ azot akış hızında ve farklı oranlarda $\mathrm{Na}_{2} \mathrm{CO}_{3}$ katalizörü kullanılarak gerçekleştirilmiş̧tir. Yapılan piroliz çalışmalarında $\% 20$ katalizör oranında en yüksek \% 9,8 biyoyağ verimi elde edilmiştir. Elde edilen bu biyoyağ FT-IR, GC-MS ve ısıl değer analizleri yapılarak karakterize edilmiştir. GC-MS sonuçları incelendiğinde biyoyağın alifatik, aromatik, keton, ester, fenol ve yağ asitleri gibi farklı fonksiyonel gruplara sahip bileşiklerden oluştuğu belirlenmiştir. FT-IR analizi GC-MS analiz sonuçlarını doğrulamıştır. Katalizör kullanımı biyoyağın ısıl değerini artırmış ve 30,57 MJ/kg olarak tespit edilmiştir.

Anahtar Kelimeler: Biyokütle, haşhaş küspesi, piroliz, biyoyağ, katalizör

\section{Catalytic Pyrolysis of Poppy Capsule Pulp in Fixed Bed Reactor}

\begin{abstract}
With the development of technology, science and industry in the history of humanity, it has been observed that the use of several energy types has increased. Gas, liquid (bio oil) and solid products (char) are obtained from pyrolysis process from biomass. Pyrolysis product is a good candidate for usage as fuel. In this study for this purpose, the pyrolysis of poppy capsule pulp for bio-oil production was conducted to investigate the effect of catalyst on liquid yield. Pyrolysis was carried out in a fixed bed pyrolysis reactor at a temperature of $500^{\circ} \mathrm{C}$, heating rate of $10^{\circ} \mathrm{C} / \mathrm{min}$, nitrogen flow rate of $1 \mathrm{~L} / \mathrm{min}$ and using different ratios of $\mathrm{Na} 2 \mathrm{CO} 3$ as catalyst. In the pyrolysis studies, the highest oil yield,9.8\%, was obtained at the rate of $20 \%$ catalyst. The obtained bio oil was characterized by FTIR, GC-MS and thermal value analysis. When the GC-MS results were examined, it was found that the bio oil was composed of compounds having different functional groups such as aliphatic, aromatic, ketone, ester, phenol and fatty acids. FT-IR analysis confirmed the GC-MS analysis results. The use of catalyst increased the thermal value of the bio oil and was determined to be 30.57 $\mathrm{MJ} / \mathrm{kg}$.
\end{abstract}

Keywords: Biomass, poppy capsule pulp, pyrolysis, bio oil, catalyst

\footnotetext{
* Sorumlu Yazar: Afyon Kocatepe Üniversitesi, Mühendislik Fakültesi, Kimya Mühendisliği Bölümü, Afyon, Türkiye, ORCID: 0000-0003-01611404,nazanyilmaz@aku.edu.tr
} 


\section{Giriş}

Dünyadaki enerji ihtiyacı artan insan ihtiyaçlarına paralel olarak artmaktadır. Enerji ihtiyacı temel olarak fosil yakıtlardan karşılanmaktadır ve bu enerji kaynakları her geçen gün tükenmektedir. Tüm fosil yakıt rezervlerinin, kömür hariç, 2042 yılına kadar tükenmiş olacağı kömür rezervlerinin 2112 yılına kadar kullanılabileceği öngörülmektedir (Abnisa ve Wan Daud, 2014). Bu sebeplerden dolayı fosil yakıtlara olan bağımlılı̆ın azaltılması ve enerjideki sürekliliğin sağlanması için alternatif enerji kaynaklarına olan ilgi artmıştır. Alternatif enerji kaynakları arasında, biyokütle enerjisi birçok yönden avantajı olan bir alternatif enerji türüdür. Bu nedenle, biyokütle enerjileri üzerine araştırmalar artmaktadır (Abnisa ve Wan Daud, Shadangi ve Mohanty, 2014).

Biyokütle enerjisi fosil yakıtlara önemli bir alternatiftir. Enerji içeriği fosil yakıtlara göre daha düşük olmasına rağmen, fosil yakıtlara göre yeniden üretilebilirliği, sürdürülebilirliği, biyobozunurluğu, düşük miktarda atık gaz çıkışı gibi önemli avantajları bulunmaktadır. Çok düşük miktarlarda $\mathrm{SO}_{2}, \mathrm{NO}_{\mathrm{x}}$ içermesi temiz bir enerji kaynağı olduğunu göstermektedir (Nayan ve ark., 2013). Biyokütle enerjisi, biyokütlenin biyoyakıt, 1 sı ve elektrik gibi faydalı enerji formlarına dönüşmesi ile elde edilir. Biyokütle bitkiler, tarım ürünleri, ağaçlar gibi tüm organik maddelerden elde edilir ve fotosentez yoluyla güneşin enerjisinin bitkilerde depolanmasıyla oluşmaktadır (Ellabban ve ark., 2014).

Biyokütleye uygulanan termokimyasal dönüşüm süreçlerinden bir olan piroliz, biyokütlenin oksijensiz ortamda katı, sıvı ve gaz ürünlere dönüştürülmesi işlemidir. Piroliz sırasında, çok sayıda reaksiyon meydana gelir. Yüksek molekül ağırlıklı bileşikler daha düşük molekül ağırlıklı kısa zincirli moleküller oluşturmak üzere parçalanırlar. Yoğuşabilen sıvı hidrokarbonlara pirolitik yağ olarak elde edilir. Pirolitik yağın miktarı ve kalitesi biyokütlenin bileşimine ve yağ içeriğine dayanmaktadır (Shadangi ve Mohanty, 2014). Biyokütle, temel olarak üç ana polimerden oluşmaktadır; selüloz, lignin ve hemiselüloz. Piroliz ile biyokütle ayrışmasının temel mekanizmaları ikiye ayrılır. Birincil mekanizmalar çar (katı) oluşumu, depolimerizasyon ve fragmentasyondur. İkincil mekanizmalar ise kraking ve yeniden polimerleşmedir (Collard ve Blin, 2014). Sonuç olarak, biyokütle kimyasal içeriğginden dolayı enerji üretimi için uygun bir maddedir. Optimum piroliz koşullarının tespit edilmesi ve uygulanması farklı biyokütleler için irdelenmesi gereken önemli bir konudur.

Literatürde farklı biyokütlelerin pirolizi ile ilgili birçok çalışma bulunmaktadır. Pirolizi çalışılan bazı biyokütleler susam sapı (Ateş ve ark., 2004), şeker pancarı küspesi (Erlich etal., 2005), pamuk çekirdeği küspesi (Pütün ve ark.., 2006), nar çekirdekleri (Uçar ve Karagöz, 2009), demirhindi çekirdekleri (Morales ve ark., 2014) ve mahua çekirdekleridir (Shadangi ve Mohanty, 2014). Literatürde haşhaş küspesinin pirolizi üzerine çok sayıda çalışma bulunmamaktadır. Haşhaş kapsülü küspesi, Afyon Alkoloid Fabrikasının temel atığıdır. Fabrika 30 yıl boyunca çalışmakta ve sürekli olarak atık sahasına küspe biriktirmektedir. Bu biyokütlenin pirolizi ile yakıta dönüştürülmesi önemli bir konudur ve bir önceki çalışmamızda (Hopa ve ark. 2016), haşhaş kapsülü küspesi 350$500^{\circ} \mathrm{C}$ sıcaklık aralığında $10^{\circ} \mathrm{C} / \mathrm{dk}$ hızla pirolize tabi tutulmuştur. Biyoyağ üretim verimi ve özellikleri irdelenmiştir. Bu çalışmada ise haşhaş kapsülü küspesinin pirolizinin katalizör ilavesi ile iyileştirilmesi hedeflenmektedir. Alkali bileşiklerinin çeşitli biyokütlelerin pirolizinde ayrışmayı kolaylaştırıldığı, ayrışma süresini kısalttığı yönünde literatür çalışmaları bulunmaktadır (K. Raveendran ve ark., 1995, ve Imran ve ark.., 2014). Shah ve ark., 2015 kavak odunu pirolizinde katalizör olarak $\mathrm{K}_{2} \mathrm{CO}_{3}$ kullanımının piroliz işlemini hızlandırdığını tespit etmişlerdir (Shah ve ark., 2015). Benzer şekilde Safar ve arkadaşları, $2019 \mathrm{~K}_{2} \mathrm{CO}_{3}$ ilavesinin biyokütlenin piroliz sırasındaki reaktivitesini artırdığını gözlemlemişlerdir (Safar ve ark., 2019). Bir diğer çalışmada $\mathrm{Na}_{2} \mathrm{CO}_{3} / \gamma^{-} \mathrm{Al}_{2} \mathrm{O}_{3} \mathrm{katalizör}$ sisteminin piroliz sonrası elde edilen biyoyağın kalorifik değerini artırdığı görülmüştür (Nguyen ve ark., 2013). Literatür çalışmaları incelendiğinde, alkali metal iyonlarının piroliz işlemine olan olumlu etkileri açıkça görülmektedir. Bu çalışmada, Afyonkarahisar bölgesinin önemli miktardaki yerel atığı olan haşhaş küspesinin pirolizinde daha önce etkileri incelenmemiş olan $\mathrm{Na}_{2} \mathrm{CO}_{3}{ }^{\prime}$ in katalizör olarak kullanımı gerçekleştirilmiştir. Çalışmanın temel amacı, $\mathrm{Na}_{2} \mathrm{CO}_{3}$ katalizörü kullanılarak haşhaş kabuğu küspesi pirolizinde sıvı ürün verimini artırmak olmuştur ve en yüksek verim ile elde edilen sıvı ürünün (biyoyağ) kalorifik değeri belirlenmiş ve GC-MS, FTIR yöntemleri ile karakterizasyon çalışmaları gerçekleştirilmiştir.

\section{Materyal ve Metot}

\subsection{Materyal}

Yapılan çalışmada kullanılan haşhaş kapsülü küspesi Afyon Alkaloidleri Fabrikasından temin edilmiştir. Fabrikadan alınan haşhaş kapsülü küspesi piroliz işlemi öncesinde $100^{\circ} \mathrm{C}$ sıcaklıkta etüvde kurutulmuştur. Katalizör olarak kullanılan toz haldeki $\mathrm{Na}_{2} \mathrm{CO}_{3} \mathrm{Eti}^{3}$ Soda A.Ş., Beypazarı firmasından temin edilmiştir. Katalizör tane boyutu $600>\mathrm{d}>150 \mu \mathrm{m}$ ' dir. Çözücü olarak diklorometan (Merck) kullanılmıştır.

\subsection{Metot}

\subsubsection{Hammaddenin Pirolizi}

Hammadde olarak seçilen haşhaş kapsülü küspesinin piroliz işlemleri; sabit yataklı piroliz reaktöründe bir önceki çalışmamızda (Hopa vd., 2016) belirlenen optimum piroliz koşulları olan $500{ }^{\circ} \mathrm{C}$ piroliz sıcaklığında, $1 \mathrm{~L} / \mathrm{dk}$ azot akış hızında ve $10{ }^{\circ} \mathrm{C} / \mathrm{dk}$ ssıtma hızında gerçekleştirilmiştir. Piroliz işlemlerinde $50 \mathrm{~g}$ haşhaş küspesi ve katalizör olarak da $\mathrm{Na}_{2} \mathrm{CO}_{3}$ kullanılmıştır. Katalizör oranının biyoyă verimi üzerine etkisini belirlemek amaciyla $\% 0, \% 5, \% 10, \% 20, \% 30, \% 40$ ve \% 50 olmak üzere farklı katalizör oranlarında deneysel çalışmalar yapılmıştır.

Haşhaş ve katalizör homojen olacak şekilde karıştırılarak reaktör içerisine yerleştirildikten sonra $10{ }^{\circ} \mathrm{C} / \mathrm{dk}$ ssıtma hızı ile piroliz sıcaklığı olan $500{ }^{\circ} \mathrm{C}$ ' ye çıkılmış ve bu sıcaklıkta $20 \mathrm{dk}$ beklenilmiş ve sonrasında piroliz işlemi sonlandırılmıştır. Yoğuşturucuda 
biriken sıvı ürün (biyoyağ) diklorometan ile yıkanarak alınmış ve sıvı toplama kabında biriken biyoyağ ile birleştirilmiştir. Biyoyağ içerisindeki su, ayrıma hunisi kullanılarak ayrılmış ve tartılarak miktarı belirlenmiştir. Biyoyağ içerisindeki çözücü ise rotary evaparatör kullanılarak uzaklaştırılmış ve miktarı belirlenmiştir. Reaktör soğutulduktan sonra açılarak içerisinde katı ürün (char) alınmış ve tartımı yapılarak miktarı belirlenmiştir. Gaz ürün miktarı ise toplam kütle denkliği kullanılarak bulunmuştur. Farklı katalizör miktarlarında deneyler tekrarlanmış ve biyoyağ, char ve gaz ürün verimleri hesaplanmıştır.

\subsubsection{Biyoyağın Karakterizasyonu Çalışmaları}

Farklı katalizör miktarlarının haşhaş küspesi pirolizi sonucu elde edilen biyoyağ verimine etkisinin incelendiği çalışmada; en yüksek biyoyağ verimin görüldüğü katalizör miktarında elde edilen biyoyağı karakterize etmek amacıyla GC-MS, FT-IR, 1Sıl değer analizleri yapılmıştır.

\subsubsection{GC-MS Analizi}

Biyoyağın kimyasal bileşenleri Shimadzu GCMS-QP2020 cihazı kullanılarak tespit edilmiştir. GC-MS analizleri Tablo 1' de verilen koşullarda gerçekleştirilmiştir.

Tablo 1. GC-MS koşulları



\subsubsection{FT-IR Analizi}

Biyoyağın yapısında bulunan fonksiyonel grupların belirlenmesi amacıyla FTIR analizi yapılmıştır. Analiz PERKIN ELMER model Fourier Transform Infrared (FT-IR) Spektrometre cihazı kullanılarak yapılmıştır.

\subsubsection{Isıl Değer Analizi}

Piroliz sonucu elde edilen biyoyağın ısıl değerinin belirlenmesi için IKA WERKE marka kalorimetre cihazı kullanılmış ve biyoyağın kalorifik değeri belirlenmiştir. 


\section{Araştırma Sonuçları ve Tartışma}

\subsection{Piroliz Çalışmasının Sonuçları}

Piroliz çalışmalarının tamamı, $500{ }^{\circ} \mathrm{C}$ piroliz sıcaklığında, $10{ }^{\circ} \mathrm{C} / \mathrm{dk}$ 1sıtma hızında ve $20 \mathrm{dk}$ bekleme süresinde gerçekleştirilmiştir. Farklı katalizör oranlarında yapılan deneyler sonucunda elde edilen sıvı ürün, katı ürün ve gaz ürün oranları

Tablo 2'de verilmiştir.

Tablo 2 Haşhaş küspesi piroliz çalışma sonuçları

\begin{tabular}{ccccc}
\hline $\begin{array}{c}\text { Katalizör/Biyokütle } \\
\text { Oranı } \\
\text { (kütlece \%) }\end{array}$ & $\begin{array}{c}\text { Biyoyağ } \\
\text { (kütlece \%) }\end{array}$ & $\begin{array}{c}\text { Katı Ürün } \\
\text { (kütlece \%) }\end{array}$ & $\begin{array}{c}\text { Gaz Ürün } \\
\text { (kütlece \%) }\end{array}$ & $\begin{array}{c}\text { Su } \\
\text { (kütlece \%) }\end{array}$ \\
\hline $\mathbf{0}$ & 5,23 & 40,23 & 38,97 & 15,57 \\
$\mathbf{5}$ & 5,16 & 40,3 & 35,74 & 18,8 \\
$\mathbf{1 0}$ & 5,55 & 40,06 & 34,99 & 19,41 \\
$\mathbf{2 0}$ & 9,8 & 40,32 & 27,42 & 22,47 \\
$\mathbf{3 0}$ & 7,31 & 41,08 & 28,71 & 22,9 \\
$\mathbf{4 0}$ & 5,93 & 41,27 & 30,34 & 22,26 \\
$\mathbf{5 0}$ & 6,44 & 40,26 & 36,51 & 16,8 \\
\hline
\end{tabular}

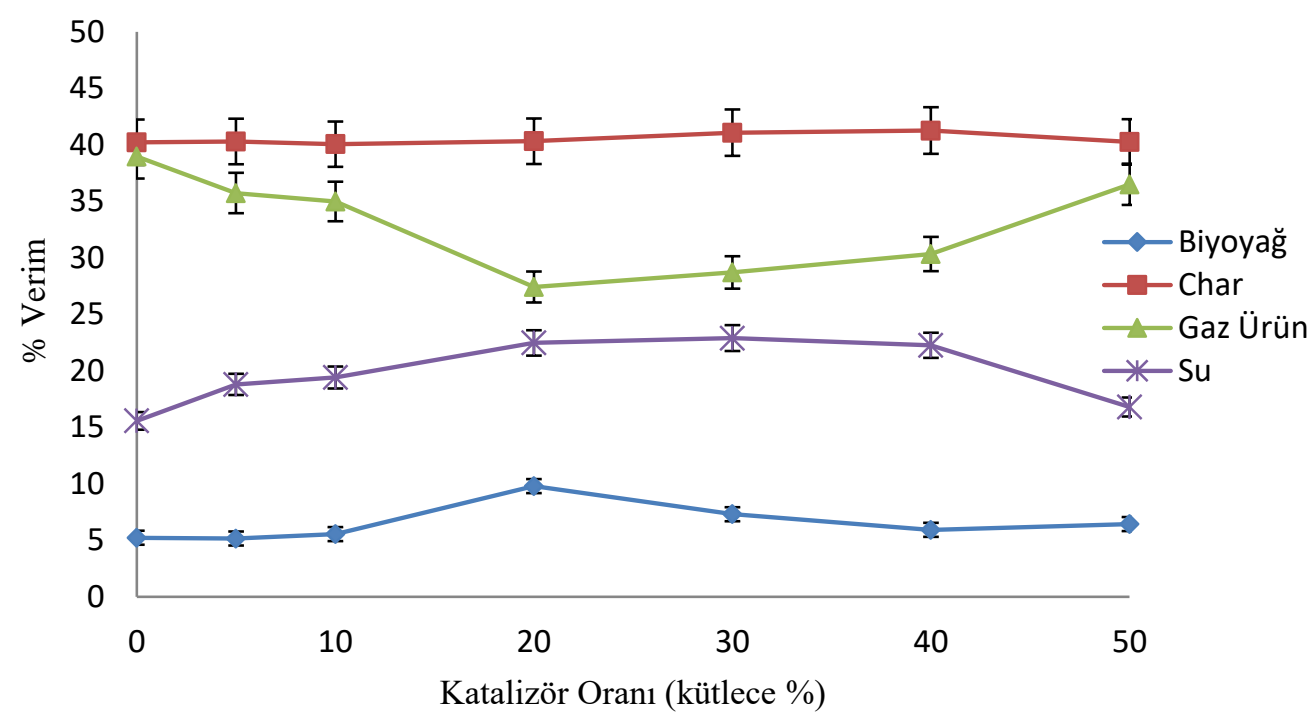

Şekil 1 Katalizör oranının piroliz ürünleri verimine etkisi.

Şekil 1' de katalizör oranının artışıyla birlikte piroliz ürünlerinin verimlerindeki değişimler gösterilmiştir. Piroliz işleminde katalizör kullanılmadığında sıvı ürün verimi \% 5 dolaylarındadır. Bu değer katalizör miktarı \% 5 ve \% 10 olduğunda yaklaşık olarak aynı seviyede kalmaktadır. Ancak $\mathrm{Na}_{2} \mathrm{CO}_{3}$ miktarı \% 20' ye artırıldığında sıvı ürün verimi yaklaşık olarak iki katına çıkarak \% 9,8 seviyesine ulaşmıştır. Katalizör miktarının sıvı ürün verimine etkisinin ifade edildiği Şekil 1 incelendiğinde en yüksek biyoyağ miktarına ağırlıkça \% 20 katalizör kullanıldığında ulaşıldığı görülmektedir. Alkali metal katalizörleri biyokütle içerisindeki selülozik bileşiklerin yapısındaki bağların kırılmasını kolaylaştırarak piroliz işlemini hızlandırmaktadır (Safar ve ark., 2019). Katalizörün yarattığı bu etki sıvı ürün veriminde artışa neden olmaktadır. Elde edilen sonuçlar literatürde yer alan alkali bileşiklerinin çeşitli biyokütlelerin pirolizinde ayrışmayı kolaylaştırıldığı, ayrışma süresini kısalttı̆̆ı yönünde çalışmalar ile uyumludur (K. Raveendran ve ark., 1995, ve Imran ve ark., 2014). 


\subsection{Biyoyağın Karakterizasyon Çalışmaları Sonuçları}

\subsection{GC-MS Analiz Sonuçları}

Katalizör kullanılarak yapılan piroliz işlemi sonucunda elde edilen biyoyağın içerisindeki bileşenler Tablo 3'de verilmiştir. Katalizörlü ve katalizörsüz yapılan piroliz işlemi sonucunda elde edilen biyoyağların GC-MS sonuçları ile tespit organik bileşik içerikleri Şekil 2'de verildiği gibi sınıflandırılmış ve karşılaş̧ırıılmıştır.

\section{Tablo 3. Biyoyağa ait GC-MS Analiz Sonuçları}

\begin{tabular}{|c|c|c|c|c|c|c|c|}
\hline $\begin{array}{l}\mathrm{RT} \\
\min \end{array}$ & $\begin{array}{c}\text { Pik } \\
\text { Alan1 } \\
(\%) \\
\end{array}$ & Bileşik & $\begin{array}{l}\text { Molekül } \\
\text { Formülü }\end{array}$ & $\begin{array}{l}\mathrm{RT} \\
\min \end{array}$ & $\begin{array}{l}\text { Pik } \\
\text { Alanı } \\
(\%) \\
\end{array}$ & Bileşik & $\begin{array}{l}\text { Molekül } \\
\text { Formülü }\end{array}$ \\
\hline 23,15 & 2,69 & 9,12-Oktadekadien-1-ol, (Z,Z)- & $\mathrm{C}_{18} \mathrm{H}_{34} \mathrm{O}$ & 9,82 & 0,74 & Fenol, 2,5-dimetil- & $\mathrm{C}_{8} \mathrm{H}_{10} \mathrm{O}$ \\
\hline 23,06 & 1,97 & 9-Oktadekenoik asit, metil ester & $\mathrm{C}_{19} \mathrm{H}_{36} \mathrm{O}_{2}$ & 9,66 & 2,93 & Fenol, 3-etil- & $\mathrm{C}_{8} \mathrm{H}_{10} \mathrm{O}$ \\
\hline 22,99 & 1,25 & $\begin{array}{l}\text { 9,12-Oktadekadienoik asit } \\
(\mathrm{Z}, \mathrm{Z})-\text {, metil ester }\end{array}$ & $\mathrm{C}_{19} \mathrm{H}_{34} \mathrm{O}_{2}$ & 9,36 & 2,11 & 2-Metillinden & $\mathrm{C}_{10} \mathrm{H}_{10}$ \\
\hline 20,96 & 2,69 & Hekzadekanoik asit, metil ester & $\mathrm{C}_{17} \mathrm{H}_{34} \mathrm{O}_{2}$ & 9,10 & 1,17 & \multirow{2}{*}{$\begin{array}{l}\text { Fenol, 2-etil- } \\
\text { Siklohekzan, (1-metiletiliden)- }\end{array}$} & $\mathrm{C}_{8} \mathrm{H}_{10} \mathrm{O}$ \\
\hline 20,67 & 2,28 & 2-Pentadekanon & $\mathrm{C}_{15} \mathrm{H}_{30} \mathrm{O}$ & 8,95 & 1,04 & & $\mathrm{C}_{9} \mathrm{H}_{16}$ \\
\hline 20,30 & 0,42 & $\begin{array}{l}\text { 1,2-Benzenedikarboksilik asit, } \\
\text { bis(2-metilpropil) ester }\end{array}$ & $\mathrm{C}_{16} \mathrm{H}_{22} \mathrm{O}_{4}$ & 8,49 & 1,70 & Fenol, 2,5-dimetil- & $\mathrm{C}_{8} \mathrm{H}_{10} \mathrm{O}$ \\
\hline 20,17 & 0,82 & Hekzametil-piranoindan & $\mathrm{C}_{18} \mathrm{H}_{26} \mathrm{O}$ & 8,17 & 2,29 & Fenol, 2-metoksi & $\mathrm{C}_{7} \mathrm{H}_{8} \mathrm{O}_{2}$ \\
\hline 19,94 & 0,59 & $\begin{array}{l}\text { 2-Pentadekanon, } 6,10,14- \\
\text { trimetil- }\end{array}$ & $\mathrm{C}_{18} \mathrm{H}_{36} \mathrm{O}$ & 7,95 & 7,59 & Fenol, 3-metil- & $\mathrm{C}_{7} \mathrm{H}_{8} \mathrm{O}$ \\
\hline 19,85 & 0,25 & Neoftadien & $\mathrm{C}_{20} \mathrm{H}_{38}$ & 7,66 & 1,58 & $\begin{array}{l}\text { 2-Siklopenten-1-one, 2,3,4- } \\
\text { trimetil- }\end{array}$ & $\mathrm{C}_{8} \mathrm{H}_{12} \mathrm{O}$ \\
\hline 18,41 & 1,03 & $\begin{array}{l}\text { 1-Hekzadekanol, 3,7,11,15- } \\
\text { tetrametil- }\end{array}$ & $\mathrm{C}_{20} \mathrm{H}_{42} \mathrm{O}$ & 7,55 & 6,02 & Fenol, 2-metil- & $\mathrm{C}_{7} \mathrm{H}_{8} \mathrm{O}$ \\
\hline 17,78 & 0,78 & n-Heksilsalisilat & $\mathrm{C}_{13} \mathrm{H}_{18} \mathrm{O}_{3}$ & 7,30 & 1,30 & 1H-Indene & $\mathrm{C}_{9} \mathrm{H}_{9} \mathrm{Cl}$ \\
\hline 16,60 & 0,42 & $\begin{array}{l}\text { 1,2-Benzendikarboksilik asit, } \\
\text { dietill ester }\end{array}$ & $\mathrm{C}_{12} \mathrm{H}_{14} \mathrm{O}_{4}$ & 7,01 & 0,97 & $\begin{array}{l}\text { 2-Siklopenten-1-one, 2-hidroksi- } \\
\text { 3-metil }\end{array}$ & $\mathrm{C}_{6} \mathrm{H}_{8} \mathrm{O}_{2}$ \\
\hline 16,57 & 0,32 & Heptadekan & $\mathrm{C}_{21} \mathrm{H}_{44}$ & 6,95 & 0,66 & Bisiklo[2.2.2]oktan, 2-metil- & $\mathrm{C}_{9} \mathrm{H}_{16}$ \\
\hline 16,46 & 0,55 & 1-Nonadekanol & $\mathrm{C}_{19} \mathrm{H}_{40} \mathrm{O}$ & 6,47 & 0,95 & 2,3-Dimetil-2-siklopenten-1-one & $\mathrm{C}_{7} \mathrm{H}_{10} \mathrm{O}$ \\
\hline 15,07 & 0,81 & Hekzadekan & $\mathrm{C}_{16} \mathrm{H}_{34}$ & 6,40 & 2,00 & 2-Siklopenten-1-one, 3,4-dimetil- & $\mathrm{C}_{7} \mathrm{H}_{10} \mathrm{O}$ \\
\hline 14,96 & 1,26 & 1-Oktadeken & $\mathrm{C}_{18} \mathrm{H}_{36}$ & 6,35 & 1,06 & $\mathrm{x}$-ethyl- $\mathrm{x}$-metil- benzen & $\mathrm{C}_{9} \mathrm{H}_{12}$ \\
\hline 13,50 & 1,13 & Tetradekan & $\mathrm{C}_{14} \mathrm{H}_{30}$ & 6,31 & 0,91 & 2-Oktanon & $\mathrm{C}_{8} \mathrm{H}_{16} \mathrm{O}$ \\
\hline 13,45 & 0,93 & 1H-Indol, 3-metil- & $\mathrm{C}_{9} \mathrm{H}_{9} \mathrm{~N}$ & 6,23 & 5,14 & Fenol & $\mathrm{C}_{6} \mathrm{H}_{6} \mathrm{O}$ \\
\hline 13,38 & 0,71 & 1-Tetradekanol & $\mathrm{C}_{14} \mathrm{H}_{30} \mathrm{O}$ & 5,81 & 0,34 & 2H-Piran-2-one, tetrahidro & $\mathrm{C}_{5} \mathrm{H}_{8} \mathrm{O}_{2}$ \\
\hline 12,15 & 1,18 & Naftalen, 2-metil- & $\mathrm{C}_{11} \mathrm{H}_{10}$ & 5,73 & 0,48 & 1-Hepten,2-metil- & $\mathrm{C}_{8} \mathrm{H}_{16}$ \\
\hline 11,91 & 2,30 & 1H-Indole & $\mathrm{C}_{8} \mathrm{H}_{7} \mathrm{~N}$ & 5,39 & 5,90 & 2-Siklopenten-1-one, 2,3-dimetil- & $\mathrm{C}_{7} \mathrm{H}_{10} \mathrm{O}$ \\
\hline 11,85 & 2,31 & Naphthalen, 1-metil- & $\mathrm{C}_{11} \mathrm{H}_{10}$ & 5,01 & 1,25 & 2(3H)-Furanon, dihidro & $\mathrm{C}_{4} \mathrm{H}_{6} \mathrm{O}_{2}$ \\
\hline 11,63 & 1,40 & 1H-Inden-1-one, 2,3-dihidro- & $\mathrm{C}_{9} \mathrm{H}_{8} \mathrm{O}$ & 4,86 & 7,48 & 2-Siklopenten-1-one, 3-metil- & $\mathrm{C}_{6} \mathrm{H}_{8} \mathrm{O}$ \\
\hline 10,76 & 0,99 & Fenol, 2,3,6-trimetil- & $\mathrm{C}_{9} \mathrm{H}_{12} \mathrm{O}$ & 4,31 & 0,44 & 2-Siklopenten-1-one, 2-metil- & $\mathrm{C}_{6} \mathrm{H}_{8} \mathrm{O}$ \\
\hline \multirow[t]{2}{*}{9,90} & 1,76 & Azulen & $\mathrm{C}_{10} \mathrm{H}_{8}$ & 4,23 & 0,45 & Benzen, 1,2-dimetil & $\mathrm{C}_{8} \mathrm{H}_{10}$ \\
\hline & & & & 4,11 & 0,82 & 2-Furanmetanol & $\mathrm{C}_{5} \mathrm{H}_{6} \mathrm{O}_{2}$ \\
\hline
\end{tabular}






Şekil 2 GC- MS sonuçları mavi; katalizörlü piroliz, kırmızı: katalizörsüz piroliz işlemi

Şekil 2'de verilen GC-MS sonuçları incelendiğinde biyoyağın alifatik, aromatik, keton, ester, fenol ve yağ asitleri gibi farklı fonksiyonel gruplara sahip bileşiklerden oluştuğu belirlenmiştir. Katalizör ile yapılan piroliz işlemi sonucunda elde edilen biyoyağ içerisindeki fenol oranının $\% 15^{\prime}$ den $\% 30$ ' a yükseldiği görülmektedir. Alkali metal katalizörlerinin biyokütle yapısındaki lignin içerisindeki bağların ayrışmasını kolaylaştırarak fenol içeriğinde artışa sebep olduğu bilinmektedir (Nzihou ve ark., 2019). Katalizör etkisiyle miktarı artan bir diğer bileşik grubu da ketonlar olmuştur. Nguyen ve arkadaşları, 2013 biyokütle pirolizinde $\mathrm{Na}_{2} \mathrm{CO}_{3} /{ }_{\gamma}-\mathrm{Al}_{2} \mathrm{O}_{3}$ katalizörü kullandıkları çalışmalarında benzer şekilde keton miktarının arttığını gözlemlemişlerdir. Katalizör kullanılmaksızın elde edilen biyoyağ içerisinde bulunan yağ asitleri, katalizör kullanılması durumunda katalizör yüzeyinde ketonlara dönüşmektedir (Nguyen ve ark., 2013).

\subsection{FT-IR Analiz Sonuçları}

Biyoyağın yapısındaki fonksiyonel grupların belirlenmesi amacıyla yapılan FT-IR analizi sonucu Şekil 4.'de verilmiştir. Şekil 4 incelendiğinde spekturumda $3200-3400 \mathrm{~cm}^{-1}$ arasındaki pik $\mathrm{O}-\mathrm{H}$ gerilme titreşimlerine aittir. $\mathrm{Bu}$ durum yapıda alkol, fenol ve karboksilik asit bileşiklerinin olduğunu gösterir. $2800-3000 \mathrm{~cm}^{-1}$ arasında yer alan pikler ise alifatik ve aromatik C-H gerilme titreşimlerine aittir. Biyoyağın yapısındaki karbonil gruplarının varlığı da $1680-1720 \mathrm{~cm}^{-1}$ arasındaki piklerden anlaşılmaktadır. Benzer şekilde spektrumda $1615-1650 \mathrm{~cm}^{-1}$ arasındaki pikler yapıda alkenlerin ve aromatik bileşiklerin varlı̆̆ını göstermektedir. 1460 ve $1380 \mathrm{~cm}^{-1}$ de yer alan pikler yapıdaki alifatik C-H gruplarının eğilme titreşimlerine aittir. 1220 ve $1270 \mathrm{~cm}^{-1}$ arasındaki pikler C-O gerilme ve $\mathrm{O}-\mathrm{H}$ eğilme titreşimlerine ait piklerdir.

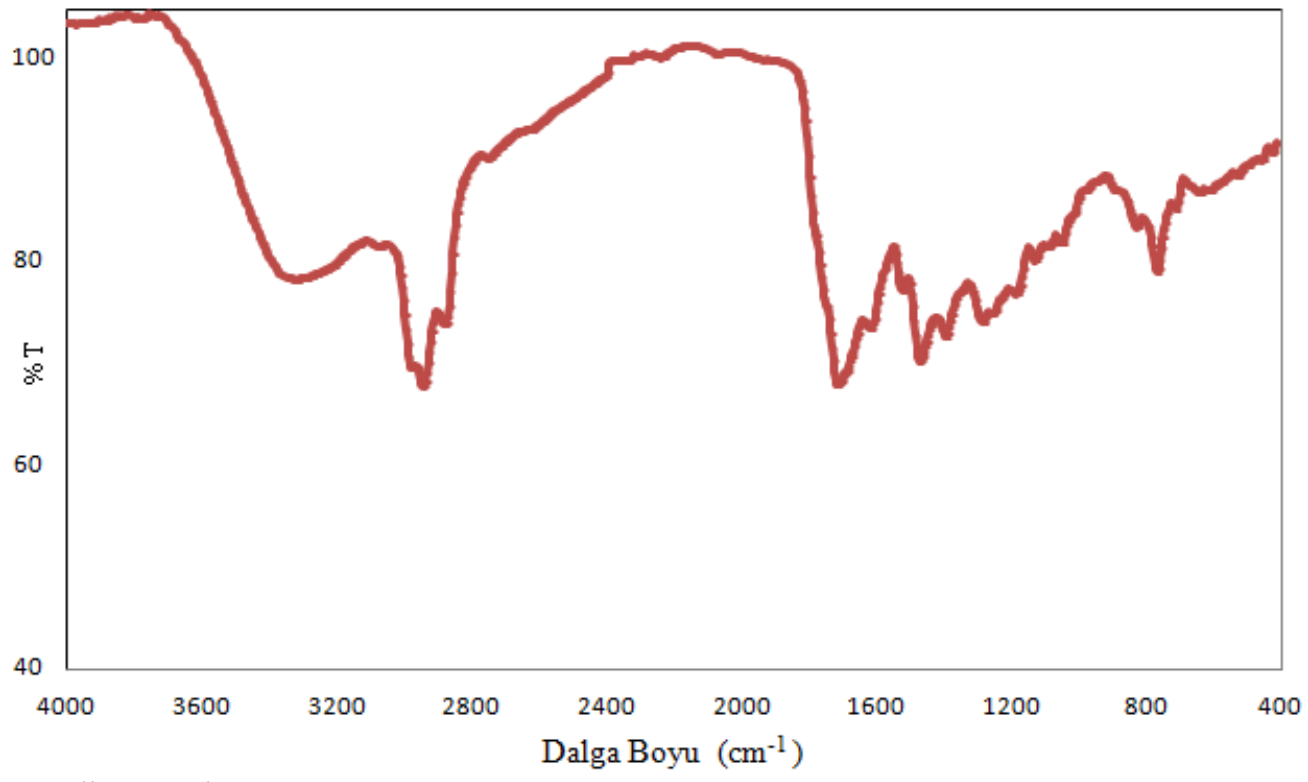

Şekil 4 FTIR analiz sonuçları 


\subsubsection{Isıl Değer Analiz Sonuçları}

Katalizörlü piroliz işlemi sonucunda en yüksek biyoyağ elde edilen \% 20 katalizör oranındaki biyoyağın kalorifik değeri tespit edilmiştir. Alt 1sıl değerinin $30,57 \mathrm{MJ} / \mathrm{kg}$ olduğu görülmüsstür. Katalizörsüz piroliz işlemi sonucunda elde edilen biyoyağın kalorifik değeri ile kıyasladığımızda (26,94 MJ7kg) 1sıl değerinin arttığı görülmüştür. Katalizör kullanımı ile biyoyağ içerisindeki alifatik hidrokarbonların artışı ve asitlerin keton gibi daha düşük oksijen içeren yapılara dönüşmesi hidrokarbon miktarını artrarak kalorifik değeri yükselten sebeplerdir (Nguyen ve ark., 2013) Bu değerler fuel oilin alt 1sıl değeri $(40,19 \mathrm{MJ} / \mathrm{kg})$ ile karşılaş̧ırıldığında biyoyağın 1 sıl değerinin düşük olduğunu belirlenmiştir. Bu nedenle fuel oil yerine doğrudan kullanımı uygun olmasa da yakıt ile belli oranlarda karıştırılarak kullanılabileceği düşünülmektedir.

\section{Sonuç}

$\mathrm{Bu}$ çalı̧̧mada farklı katalizör miktarının haşhaş küspesi pirolizi ile elde edilen biyoyağ verimi üzerine etkisi incelenmiştir. Bu amaçla $500{ }^{\circ} \mathrm{C}$ sıcaklıkta $10{ }^{\circ} \mathrm{C} / \mathrm{dk}$ 1sıtma hızında ve $1 \mathrm{~L} / \mathrm{dk}$ azot akış hızında piroliz işlermleri gerçekleştirilmitir. $\% 0,5,10,20,30,40,50$ olmak üzere 7 farkl $\mathrm{Na}_{2} \mathrm{CO}_{3}$ katalizör oranında denemeler yapılmış en yüksek biyoyağ elde edilen katalizör miktarı belirnemiştir. En yüksek biyoyağ verimindeki biyoyağa GC-MS, FT-IR ve ısıl değer analizleri yapılarak karakterize edilmiştir.

Piroliz çalışmaları sonuçları incelendiğinde en yüksek biyoyağ veriminin $(\% 9,8) \quad \% 20$ oranında katalizör kullanıldığında elde edildiği görülmüştür. Katalizör kullanılmadığında elde edilen \% 5,23 olan biyoyă̆ verimin kullanılan katalizör miktarının \%20'ye çıkarılması ile arttığı görülmektedir. Kullanılan katalizörün piroliz işlemi sırasında ayrışmayı kolaylaştırdığı ve böylelikle biyoyağ ürün verimi artırdığını söyleyebiliriz.

Biyoyağın içerdiği bileşenlerin belirlenmesi amacıyla yapılan GC-MS analiz sonuçlarına göre, katalizörsüz çalışma referans alındığında alifatik bileşiklerde $\% 8,71$ 'den $\% 10,86$ 'ya, fenol bileşiklerde $\% 15,87$ 'den $\% 28,57$ 'ye ve keton da ise $\% 19,15$ 'den 25,01 'e yükselme olduğu saptanmıştır. Yapılan FT-IR analizi sonucu elde edilen spektrum incelendiğinde, biyoyağın yapısında alkol, fenol, karboksilik asit ve aromatik bileşiklerin olduğunu göstermiştir. FT-IR analiz sonuçları ile GC-MS analiz sonuçları birbirini doğruladığı görülmektedir.

Biyoyağın 1sıl değerinin belirlenmesi için yapılan analiz sonucunu incelediğimizde katalizör kullanıldığında biyoyağın 1sıl değerinin $26,94 \mathrm{MJ} / \mathrm{kg}$ 'dan 30,57 Mj/kg ‘a artığı görülmüşütr. Katalizör kullanımı biyoyağ verimini artırmak ile birlikte biyoyağın kalorifik değerini de artırmıştır.

\section{Kaynakça}

Agrawalla, A., Kumar, S., \& Singh, R. K. (2011). Pyrolysis of groundnut de-oiled cake and characterization of the liquid product. Bioresource technology, 102(22), 10711-10716.

Ateş, F., Pütün, E., \& Pütün, A. E. (2004). Fast pyrolysis of sesame stalk: yields and structural analysis of bio-oil. Journal of Analytical and Applied Pyrolysis, 71(2), 779-790.

Collard, F. X., \& Blin, J. (2014). A review on pyrolysis of biomass constituents: Mechanisms and composition of the products obtained from the conversion of cellulose, hemicelluloses and lignin. Renewable and Sustainable Energy Reviews, 38, 594-608.

Hopa, D. Y., Yılmaz, N., Alagöz, O., Dilek, M., Helvac1, A., \& Durupınar, Ü. (2016). Pyrolysis of poppy capsule pulp for bio-oil production. Waste Management \& Research, 34(12), 1316-1321.

Ellabban, O., Abu-Rub, H., \& Blaabjerg, F. (2014). Renewable energy resources: Current status, future prospects and their enabling technology. Renewable and Sustainable Energy Reviews, 39, 748-764.

Erlich, C., Öhman, M., Björnbom, E., \& Fransson, T. H. (2005). Thermochemical characteristics of sugar cane bagasse pellets. Fuel, 84(5), 569-575.

Imran, A., Bramer, E. A., Seshan, K., \& Brem, G. (2014). High quality bio-oil from catalytic flash pyrolysis of lignocellulosic biomass over alumina-supported sodium carbonate. Fuel processing technology, 127, 72-79.

Raveendran, K., Ganesh, A., \& Khilar, K. C. (1995). Influence of mineral matter on biomass pyrolysis characteristics. Fuel, 74(12), 1812-1822.

Morales, S., Miranda, R., Bustos, D., Cazares, T., \& Tran, H. (2014). Solar biomass pyrolysis for the production of bio-fuels and chemical commodities. Journal of Analytical and Applied Pyrolysis, 109, 65-78.

Nayan, N. K., Kumar, S., \& Singh, R. K. (2013). Production of the liquid fuel by thermal pyrolysis of neem seed. Fuel, 103, 437-443.

Nguyen, T. S., Zabeti, M., Lefferts, L., Brem, G., \& Seshan, K. (2013). Conversion of lignocellulosic biomass to green fuel oil over sodium based catalysts. Bioresource technology, 142, 353-360.

Nzihou, A., Stanmore, B., Lyczko, N., \& Minh, D. P. (2019). The catalytic effect of inherent and adsorbed metals on the fast/flash pyrolysis of biomass: A review. Energy, 170, 326-337.

Pütün, E., Uzun, B. B., \& Pütün, A. E. (2006). Fixed-bed catalytic pyrolysis of cotton-seed cake: effects of pyrolysis temperature, natural zeolite content and sweeping gas flow rate. Bioresource Technology, 97(5), 701-710. 
Safar, M., Lin, B. J., Chen, W. H., Langauer, D., Chang, J. S., Raclavska, H., ... \& Pétrissans, M. (2019). Catalytic effects of potassium on biomass pyrolysis, combustion and torrefaction. Applied Energy, 235, 346-355.

Shadangi, K. P., \& Mohanty, K. (2014). Comparison of yield and fuel properties of thermal and catalytic Mahua seed pyrolytic oil. Fuel, 117, 372-380.

Shah, M. H., Deng, L., Bennadji, H., \& Fisher, E. M. (2015). Pyrolysis of potassium-doped wood at the centimeter and submillimeter scales. Energy \& Fuels, 29(11), 7350-7357.

Uçar, S., \& Karagöz, S. (2009). The slow pyrolysis of pomegranate seeds: The effect of temperature on the product yields and bio-oil properties. Journal of analytical and applied Pyrolysis, 84(2), 151-156. 